\title{
A Lifelong and Life-Wide Framework for Adult Literacy Education
}

Stephen Reder, Portland State University

In this forum, I argue that adult literacy education needs to be repositioned within a new framework of lifelong and life-wide learning, a framework in which new policies are formulated, programs are designed and evaluated, and research is funded and carried out. To appreciate how much this suggested framework differs from the neoliberal framework in which adult education is currently embedded, it is worth considering briefly how neoliberalism has gained its foothold in (some would say its stranglehold on) adult education.

Many who started their careers in adult education in the 1970s or before were initially drawn into the field by the strong connections among adult literacy, social justice, community development and human empowerment. Influenced by visionaries and activists such as Paulo Freire, adult educators once aimed for broad programmatic outcomes in social, economic and political arenas, both in the United States and around the world. The heady optimism and activism of adult education started to evaporate in the 1980s as the hegemony of neoliberalism developed, prioritizing "free markets" as the mechanism for solving a wide range of social, economic and educational problems.

Neoliberalism made inroads into all levels of education, emphasizing the "knowledge economy" that valued individuals only as economic actors, essentially disregarding the importance of education for a wide range of individual and societal outcomes (Tett \& Hamilton, 2019). Neoliberalism narrowed the purpose of adult education to increasing human capital as measured by increases in educational attainment and standardized literacy and numeracy test scores. National and cross-national assessment surveys of adult skills, education, employment and earnings (e.g., NALS, IALS, ALL, PIAAC) and a large body of research seemed to confirm the importance of both education and literacy and numeracy skills for economic success in countries around the world (e.g., Commission on Skills of the American Workforce 1990; Hanushek 2015; Kirsch et al 2007). In opposition to this juggernaut, strong critiques have been written about this burgeoning neoliberal framework (e.g., Street 1985, 1999; Hamilton 2012; Tett \& Hamilton 2019).

The neoliberal framework heavily influenced public funding of adult education in the United States and other countries. In the United States, the Workforce Investment Act (WIA) and later the Workforce Innovation and Opportunity Act (WIOA) legislation funded programs tailored to help adult students increase their standardized test scores, obtain high school equivalency, find 
employment or enter vocational training or postsecondary education. Practitioners often report that these programs are designed primarily to meet the needs of employers and workforce development stakeholders rather than the needs of the adult students. To be sure, many students have goals that are consistent with the workforce development agenda, but many other adults needing stronger basic skills have other learning goals and motivations. From what I've observed, many practitioners initially resisted the rigid testing and accountability regimes that WIA/ WIOA imposed on their programs, but over time these regimes became more familiar and more widely accepted presumably because there were few alternative sources of program funding.

Practitioners and program administrators often report difficulties working within the WIOA framework to meet the needs of all potential adult education students they could serve. WIOA's funding and compliance regimes often effectively prevent programs from serving those most in need. In responding to these persistent limitations over many years, programs have slowly lost their capacity to attract funding that connects basic skills instruction with other social aims (e.g., social justice). Similarly, difficulties obtaining funding to study aspects of adult education not directly tied to WIOA outcomes can discourage young scholars who want to take a more critical stance from careers as adult education researchers. These challenges can make it more difficult for the field to attract new practitioners and researchers.

We need funding for basic skills programs that are designed to meet a broader set of lifelong and lifewide goals of adults and communities. The two key concepts here are lifelong and life-wide. I will consider each in turn. Lifelong learning is often understood to refer to learning that takes place at any age or life stage. In this forum, I also use the term to refer to learning and changes that occur over substantial time periods across the lifespan. Program impact on life outcomes depends of course on the outcomes measured and the elapsed times after program exit when they are measured. Let me illustrate the importance of this time lag with two examples, one from public housing research and one from my own research on adult education.

The Move to Opportunity (MTO) experiment from the mid-1990s provides an example from public housing research. There is abundant evidence that individuals living in high-poverty neighborhoods fare worse than individuals living in lower-poverty neighborhoods in terms of a broad range of social and economic outcomes. In response to these neighborhood disparities, The U. S. Department of Housing and Urban Development conducted the MTO experiment, in which a randomly selected group of families living in housing projects in high-poverty neighborhoods were offered subsidized housing vouchers to move to lower-poverty neighborhoods. By generating large differences in neighborhoods for comparable families in public housing, the MTO experiment provided an opportunity to evaluate the impact of improving neighborhood environments for low-income families in the 1990s (Ludwig et al., 2013).

Initial evaluations of the MTO experiment found that moving to lower-poverty neighborhoods produced substantial improvements in health and well-being but no significant changes in the employment or earnings of youth or adults in the years immediately following the intervention. Chetty, Hendren, and Katz (2016) analyzed much longer-term outcomes in the administrative data records of MTO study participants. They found a very different result for employment and earnings: the young children of the families that moved 
to lower-poverty neighborhoods had, as adults some 20 years later, substantially higher levels of education, employment and earnings than children in the control group who did not move into such neighborhoods.

Although there are many other interesting findings from the seminal MTO research, we already can see some important points relevant to our discussion. One important point is that program impacts take different amounts of time to develop after the intervention depending on the outcome measure followed. For the MTO experiment, the employment and earnings benefits of moving to lower-poverty neighborhoods were experienced only by the young children not the adults of the families moving to lower-poverty neighborhoods and those impacts became evident only a long time after the move took place. Such a transgenerational impact has often been suggested for adult literacy programs, whereby programs positively affect the educational and literacy outcomes of the adult students' young children (Sticht \& Armstrong, 1994).

A second example of why it is important to evaluate outcomes long after adults go through programs or interventions comes from my own research on the impact of adult education programs (Reder, 2019). In this work, my colleagues and I followed a representative sample of low-education adults living in a metropolitan area over nearly a decade, collecting multiple waves of periodic in-home interviews, skills assessments and linked administrative data. Quasi-experimental comparisons were made of the outcome trajectories of those who chose to participate in adult education programs and of those who did not. The analyses indicated that program impacts on literacy skills, employment and earnings took about five years to mature fully after students left programs. The large long-term impacts of programs on earnings averaged about \$10,000/year (in 2017 dollars) but were evident only in the long-term not in the short-term outcomes.

These examples illustrate that the impacts of interventions or programs can be substantial but can take time to develop after the experience in question. If evaluations are conducted using only short-term outcomes measures, they may miss much of the actual impact that programs are having. This happens consistently in adult education, where test score gains, educational transitions and employment changes are generally measured shortly after program exit. These literally short-sighted accountability regimes miss the longer-term impact that programs are actually having. Anecdotally, many adult education teachers can see longer-term impacts whenever they, in a chance meeting with a former student, hear comments such as "Oh Mr. Wheeler, you have no idea how your class changed my life!"

So, we need to approach lifelong learning in adult education not only in terms of offering instruction at diverse ages and stages of the lifespan, but also in terms of designing, evaluating and funding programs based on long-term outcomes. Although short-term outcomes may be useful for some programmatic purposes, we must not rely on them as our only or even as our primary measures of student learning and program impact. When I talk with practitioners and program administrators about doing this, they rightly ask about how programs can be held accountable for longer-term outcomes when so many other experiences and factors intervene between program exit and longterm outcome measurement. This is an important topic worth careful consideration and discussion. Another good question is how long-term outcome tracking might be efficiently implemented given how difficult and costly it often is for programs to 
collect and report just the short-term outcomes required by WIOA funding. One promising technique here would be to use smartphone technology to collect periodic follow-up data from students (with permission, of course) relevant to the outcome measures.

Life-wide learning and outcome measures are also essential for adult education. The neoliberal focus of publicly funded programs in the United States is on employment, high school equivalency, and postsecondary training and education. Although these outcomes address the goals of many adults, many adults with basic skills needs have other goals that cannot readily be served within this framework. To begin with, millions of adults are not in the workforce due to age, disabilities, poor health, family care responsibilities, etc. Other adults wish to improve their basic skills for other reasons entirely, such as assisting their children with schoolwork, understanding and addressing their own health issues or those of family members, or participating in civic affairs such as voting or understanding political issues.

There is good reason to believe that suitably designed adult education programs could help millions of adults meet their life-wide goals. Authentic literacy instruction, structured around the literacy activities and purposes in individual adults' lives, is associated with increased engagement in literacy practices after students leave the program (Purcell-Gates, Degener, Jacobson, \& Soler, 2002). Besides helping adults to apply their basic skills in activities to meet their personal goals, there may be important side effects of their increased literacy engagement. Recent research indicates that broad social outcomes such as social trust, general health, political efficacy and volunteerism - to name but a few - are positively associated with basic skills including literacy and numeracy (OECD, 2013). Although educational attainment itself is a driver of many of these social outcomes, basic skills are also an important determinant of these social outcomes at each level of education, including individuals in the target population for adult education (Reder, 2017). Beyond this, adults' everyday use of their basic skills is associated with positive social outcomes when both educational attainment and assessed levels of literacy or numeracy are taken into account (Jonas, 2018; Reder, 2017, 2019). It is thus quite plausible that a more life-wide approach to adult education could help individuals meet their personal goals and help foster broader social outcomes such as general health, social trust, political efficacy and civic engagement.

We need to expand adult education by broadening our lens on its programmatic outcomes in both the lifelong and life-wide dimensions. There will be important benefits to expanding adult education in these ways. By designing and evaluating programs in terms of the longerterm outcomes they produce, it becomes easier to assess the actual impact that programs have, which in turn could make a more compelling case for funding. By using longer-term outcomes as criterion measures in program improvement processes, it should become easier to identify more promising program designs and implementations, thereby strengthening programs over time. By lengthening the impact intervals for programs, we may be able to see not only the full impact of programs on adults' lives, we may be able to include the intergenerational effects of improving parents' basic skills.

By expanding the programmatic focus of publicly funded adult education in the United States from its current narrow focus on human capital growth to a broader life-wide set of goals, programs could serve millions more adult learners in need of better basic skills. This expansion would not 
only help adults with a broader range of personal goals to improve their basic skills, it would likely increase overall levels of literacy and numeracy engagement in the population with attendant increases in general health, social trust, political efficacy and civic engagement. These improved social outcomes would benefit not only the individual students but also their neighborhoods and society more generally. Think about the community and societal importance of higher overall levels of general health, social trust, political efficacy and civic engagement.

What are some of the key strategic considerations in trying to advocate for this sweeping reform of adult education in the United States? We should position this reform as adding to rather than replacing existing WIOA programs. With their narrow and short-term focus on employment, WIOA programs are part of a workforce development system that helps meet the needs of many adults in the workforce and their employers. This serves an important function in our economy and society. We nevertheless need public funding for other kinds of adult basic skills programs organized in a lifelong and life-wide framework. It is essential that this expansion to the adult education system is made through an evidence-based process from the very beginning, systematically addressing questions about program design and quality in terms of adult students' long-term outcomes. It might be helpful to have a federal office or agency overseeing the implementation and evaluation of these lifelong and life-wide adult education programs. We may need both public and private funding to support the basic and applied research that can drive the evidence-based system.

By broadening the lens on program outcomes in these ways, I hope some of the optimism and activism of an earlier era of adult literacy education can re-emerge and find traction in a more expansive system of adult education with a lifelong and life-wide focus on individuals' life outcomes. 


\section{References}

Chetty, R., Hendren, N., \& Katz, L. F. (2016). The effects of exposure to better neighborhoods on children: New evidence from the Moving to Opportunity Experiment. American Economic Review, 106(4), 855-902.

Commission on the Skills of the American Workforce (1990). America's choice: High skills or low wages. Washington, DC: National Center on Education and the Economy.

Hanushek, E. A. (2017). For long-term economic development, only skills matter. IZA World of Labor, 343. doi: 10.15185/izawol.343

Jonas, N. (2018). Numeracy practices and numeracy skills among adults. OECD Education Working Papers, No. 177. Paris: OECD Publishing. doi: 10.1787/8f19f c9f-en.

Kirsch, I. S., Braun, H., Yamamoto, K., \& Sum, A. (2007). America's perfect storm: Three educational forces changing our nation's future.

Ludwig, J., Duncan, G. J., Gennetian, L. A., Katz, L. F., Kessler, R. C., Kling, J. R., \& Lisa Sanbonmatsu, L. (2013). Long-term neighborhood effects on low-income families: Evidence from Moving to Opportunity. American Economic Review, 103(3): 226-31.

OECD (2013). First results from the Survey of Adult Skills. Paris: OECD Publishing. doi:10.1787/9789264204256-en.
Purcell-Gates, V., Degener, S. C., Jacobson, E. and Soler, M. (2002). Impact of authentic adult literacy instruction on adult literacy practices. Reading Research Quarterly, 37(1): 70-92. doi:10.1598/RRQ.37.1.3

Reder, S. (2019). Developmental trajectories of adult education students: Implications for policy, research, and practice. In D. Perin (Ed.), Wiley handbook of adult literacy (pp. 429-450). Hoboken, NJ: Wiley Blackwell.

Reder, S. (2017). Adults' engagement in reading, writing and numeracy practices. Retrieved from http://archives. pdx.edu/ds/psu/21693.

Sticht, T. \& Armstrong, W. (1994). Adult literacy in the United States: A compendium of quantitative data and interpretive comments. Retrieved from https:// www.researchgate.net/publication/234722064_Adult_ Literacy_in_the_United_States_A_Compendium_of Quantitative_Data_and_Interpretive_Comments

Street, B. V. (1999). Literacy, economy and society. Working Paper No. 1. Montreal: Centre for Literacy.

Street, B. V. (1985). Literacy in theory and practice. Cambridge: Cambridge University Press.

Tett, L., \& Hamilton, M. (Eds.) (2019) Resisting neoliberalism in education: Local, national and transnational perspectives. Bristol University Press. 